\section{A particular way with words}

\author{
Robert W. Cahn
}

The Art of Scientific Writing: From the Student Report to Professional Publications in Chemistry and Related Fields. By Hans F. Ebel, Claus Bliefert and William E. Russey. VCH: 1987. Pp. 493. Hbk DM98, \$59.95, £39.25; pbk DM48, $\$ 24.95, £ 19.25$.

PEOPLE who draft patents are apt to refer to the "state of the art", by which they mean current technique, technology, design, disposition, proportion, processing, assembly and the like. The book under review covers the state of the art of scientific communication, and going beyond that it also surveys the strategy and tactics of English style as practised by skilled (and unskilled) scientific communicators.

Books of this kind fall into two broad categories: reference manuals (such as the Chicago Manual of Style or Copy-Editing - The Cambridge Handbook by Judith Butcher) and discursive guides to good usage (such as The Chemist's English by Robert Schoenfeld). Although Ebel and his colleagues have contrived to steer a median course between these extremes, they do aim more towards systematic exposition and exhaustive instruction. They also seek to explain why as well as show how, and in these stated objectives they have succeeded.

The authors have a passion, not only for clarity and economy of style, but also for precision and consistency. Their attitude to both scientific writing and editing is reminiscent of the words of William Blake: "He who would do good to another must do it in Minute Particulars. General Good is the plea of the scoundrel, hypocrite and flatterer; for Art and Science cannot exist but in minutely organized Particulars". (Is that last full point in the correct place?)

The book treats, essentially, three broad themes: how to organize a report, dissertation, paper or book and how to achieve maximum clarity in the enterprise (the detailed advice on dissertations will be especially useful to anxious graduate students, who should find the paperback price accessible); the practicalities of drafting, correcting, typing or printing, drawing illustrations and chemical molecules, and proof-reading (the reasoned advocacy of computers as word-processing tools is particularly helpful); and the accepted conventions of citing the literature, using units correctly, setting out mathematical expressions, laying out tables, abbreviation of scientific terms, and chemical nomenclature. Although the authors are chemists and pay special attention to chemists' difficulties, other readers merely need to do a little judicious skipping. In addition, there are 100 pages of appendices, mostly factual but also including a concise discussion of good English usage.

The authors certainly practise what they preach: I found only a single misprint and one grammatical solecism (" $x$ is comprised of $\left.y^{\prime \prime}\right)$.

On just one aspect of style the authors, uncharacteristically, blow both hot and cold: this is the vexed issue of the active versus the passive voice. While themselves preferring and occasionally using the active voice, they claim that their task is to describe the world as they find it and

\section{Out of this world}

\section{Maxine Clarke}

Sex and Scientific Inquiry. Edited by Sandra Harding and Jean F. O'Barr. University of Chicago Press: 1987. Pp.317. Hbk \$24.95, £19.95; pbk \$10.95, £8.75.

IT Is difficult to guess at whom this book is aimed. From its title, one might imagine that it sets out to do the same job for women scientists that Germaine Greer did for artists. But although sex bias is one of the issues discussed here, the mish-mash of articles fails to do more than frustrate the reader.

All the contributions in this volume have been reprinted from Signs: Journal of Women in Culture and Society, and they address an enormous range of topics. The coverage is haphazard and arbitrary; thus, for example, Schiebinger's essay, in which the numbers of women scientists in various disciplines between 1928 and 1938 are analysed, stands alone, frozen in time, and is nowhere complemented by an account of how things have changed or how they might change in the future.

Lack of homogeneity is a common problem for editors of an anthology such as this. In tackling it, Sandra Harding and Jean O'Barr have restricted themselves to an introduction and, bemusingly, a footnote to two of the 15 articles in the book, setting out the authors' conclusions in a couple of sentences.

In the introduction, which by default is the only place where a clue to the philosophy of the collection might reside, Harding and O'Barr say the articles they have chosen reflect "five major focuses" of feminist concern in relation to science. These are: the social structure of science; uses and abuses of technology; bias; sexual meaning; and "epistemology and metatheory". Each of these topics is addressed by several authors, many of that most of us prefer impersonal (and thus passive) constructions when describing our work. "The mixture was distilled" I accept. But I think that the phrase "It is thought that" is an abomination. We all of us, in writing about science, describe what was done and say what we think, and why. Putting opinions in the passive voice seeks to impose a semblance of objectivity on something that by its nature cannot be objective. As a former editor of the Guardian newspaper once (nearly) wrote: "Facts are sacred (and passive), opinions are free (and active)"

Robert W. Cahn is in the Department of Materials Science and Metallurgy, University of Cambridge, Pembroke Street, Cambridge CB2 $3 Q Z, U K$

whom use the style of writing in which several statements, each with a reference number, are strung together in a paragraph that generally ends with a takehome message along the lines of "chemistry sets help children develop different skills and aspirations than do Barbie dolls" (p.23). The clarity of argument in the essays is obscured almost totally by the use of jargon and of ex cathedra statements.

I would have found it easier to be sympathetic to the book if the authors had tried in some way to present alternatives rather than to analyse obscure, academic theses so exhaustively. Education, for example, is a subject barely touched on. An essay on the biological differences between men and women, and whether they are inherited or social, does not try to address what might be done to change attitudes. The ideological arguments of the essay are irrelevant in the light of the fact that many women have not begun to think about a scientific (or any other) career at the age of 15 . But their interests would be well served by a more flexible education system that would allow them to take up science in their mid-20s, particularly those women who have suffered from class bias. Although the points discussed in the essay on sex differences may well be valid, they have less bearing on the problems that exist in the real world than other lines of argument might have done.

With a modestly priced paperback edition, the book is presumably intended for a general readership and, again presumably, aims to say something new to that readership. But with its disregard for the pragmatic and its espousal of the didactic, I imagine that it will be read only by feminists in academia and not by the browser in the bookshop. That is a pity, for what is needed is a book that is relevant to women scientists in the 1980 s, not one that is stuck in the consciousnessraising era of ten years ago.

Maxine Clarke is the News and Views editor of Nature. 